\title{
Normothermic Ex-vivo Liver Perfusion and the Clinical Implications for Liver Transplantation
}

\author{
Clifford Akateh*1, Eliza W. Beal ${ }^{1}$, Bryan A. Whitson ${ }^{2}$ and Sylvester M. Black ${ }^{3}$ \\ ${ }^{1}$ General and Gastrointestinal Surgery, Department of Surgery, The Ohio State University Wexner Medical Center, \\ Columbus, Ohio, USA; ${ }^{2}$ Division of Cardiac Surgery, Department of Surgery, The Ohio State University Wexner Medical Center, \\ Columbus, Ohio, USA; ${ }^{3}$ Division of Transplant Surgery, Department of Surgery, The Ohio State University Wexner Medical Center, \\ Columbus, Ohio, USA
}

\begin{abstract}
Despite significant improvements in outcomes after liver transplantation, many patients continue to die on the waiting list, while awaiting an available organ for transplantation. Organ shortage is not only due to an inadequate number of available organs, but also the inability to adequately assess and evaluate these organs prior to transplantation. Over the last few decades, ex-vivo perfusion of the liver has emerged as a useful technique for both improved organ preservation and assessment of organs prior to transplantation. Large animal studies have shown the superiority of ex-vivo perfusion over cold static storage. However, these studies have not, necessarily, been translatable to human livers. Small animal studies have been essential in understanding and improving this technology. Similarly, these results have yet to be translated into clinical use. A few Phase 1 clinical trials have shown promise and confirmed the viability of this technology. However, more robust studies are needed before ex-vivo liver perfusion can be widely accepted as the new clinical standard of organ preservation. Here, we aimed to review all relevant large and small animal research, as well as human liver studies on normothermic ex-vivo perfusion, and to identify areas of deficiency and opportunities for future research endeavors.
\end{abstract}

Citation of this article: Akateh C, Beal EW, Whitson BA, Black SM. Normothermic ex-vivo liver perfusion and the clinical implications for liver transplantation. J Clin Transl Hepatol 2018;6(3):276-282. doi: 10.14218/JCTH.2017.00048.

\section{Introduction}

Despite significant improvements in graft and patient survival rates, there is still a large discrepancy between the available organs for transplant and the number of candidates on the waiting list for transplant. In the United States, in 2016, there were 14,432 patients listed for liver transplantation and 7,841 liver transplants preformed, leaving 6,591 patients without

Keywords: Liver; Transplantation; Ex-vivo perfusion.

Abbreviations: $D C D$, donation after cardiac death; ECMO, extracorporeal membrane oxygenation; HMP, hypothermic machine perfusion; IRI, ischemiareperfusion injury; NMP, normothermic machine perfusion; SCS, static cold storage; UW, University of Wisconsin solution.

Received: 19 July 2017; Revised: 7 February 2018; Accepted: 1 March 2018

*Correspondence to: Clifford Akateh, General and Gastrointestinal Surgery, Department of Surgery, The Ohio State University Wexner Medical Center, 395 W 12th Ave, Room 654, Columbus, OH-43210-1267, USA. Tel: +1-614-2938704, Fax: +1-614-293-4063, E-mail: clifford.akateh@osumc.edu available organs for transplantation. ${ }^{1}$ Unfortunately, the number of deceased organ donors appears to have reached a plateau. ${ }^{1-4}$ As such, over the past three decades, many centers have pursued several different methods to increase the available donor pool for transplantation.

One such area involves increasing the use of marginal donor organs. While most donor organs can generally tolerate variable durations of static cold storage (SCS), and its associated ischemia/reperfusion injury (IRI), marginal organs have been known to do poorly under such circumstances. ${ }^{5-7}$ This has led to renewed interest in techniques that would improve the quality of donor organ preservation and, thus, improve the suitability of marginal donor organs for transplantation. The concept of machine perfusion was introduced by Alexis Carrel and Charles Lindberg in 1935, in their work "The Culture of Organs", ${ }^{8}$ and later expanded upon by Belzer, ${ }^{9}$ who also was a pioneer in hypothermic machine perfusion (HMP).

Hypothermic ex-vivo perfusion of the kidney produced impressive results and resulted in increases in the number of organs available for transplantation. Similar advances have not translated to liver transplantation, however, where SCS remains the prominent preservation modality outside of clinical trials. Unlike kidneys, livers have a much higher metabolic activity and tolerate prolonged ischemia poorly. With their high metabolic demand, donor livers have been more challenging to perfuse and sustain under normothermic conditions. Research into normothermic ex-vivo perfusion has continued over the last five decades. With advancements in the perfusion technology and the understanding of organ physiology, it has seen renewed interest as a platform to preserve, assess and potentially repair marginal donor organs. ${ }^{10}$

There are a number of devices currently in clinical use for this procedure, including the Organ Assist's Liver Assist (with an adjustable temperature range from $10^{\circ}-38^{\circ} \mathrm{C}$; for performance of hypothermic and normothermic perfusion), ${ }^{11}$ the OrganOx Metra (normothermic perfusion) ${ }^{12}$ and the Transmedics OCS $^{\mathrm{TM}}$ Liver Portable Perfusion System (normothermic perfusion). ${ }^{13}$ Overall, these systems consist of a hepatic artery +/- portal vein pump, a perfusate reservoir and an oxygenating chamber of oxygenated perfusion (Fig. 1).

Although there is ongoing debate over the best preservation/perfusion temperature, normothermic (liver) machine perfusion (NMP or normothermic machine liver perfusion) appears to be gaining more traction and acceptance, compared to subnormothermic perfusion and hypothermic machine perfusion (HMP). It is, thus, likely to become the standard of ex-vivo machine perfusion. Regardless of approach, it has 
Akateh C. et al: Ex-vivo liver perfusion - a literature review

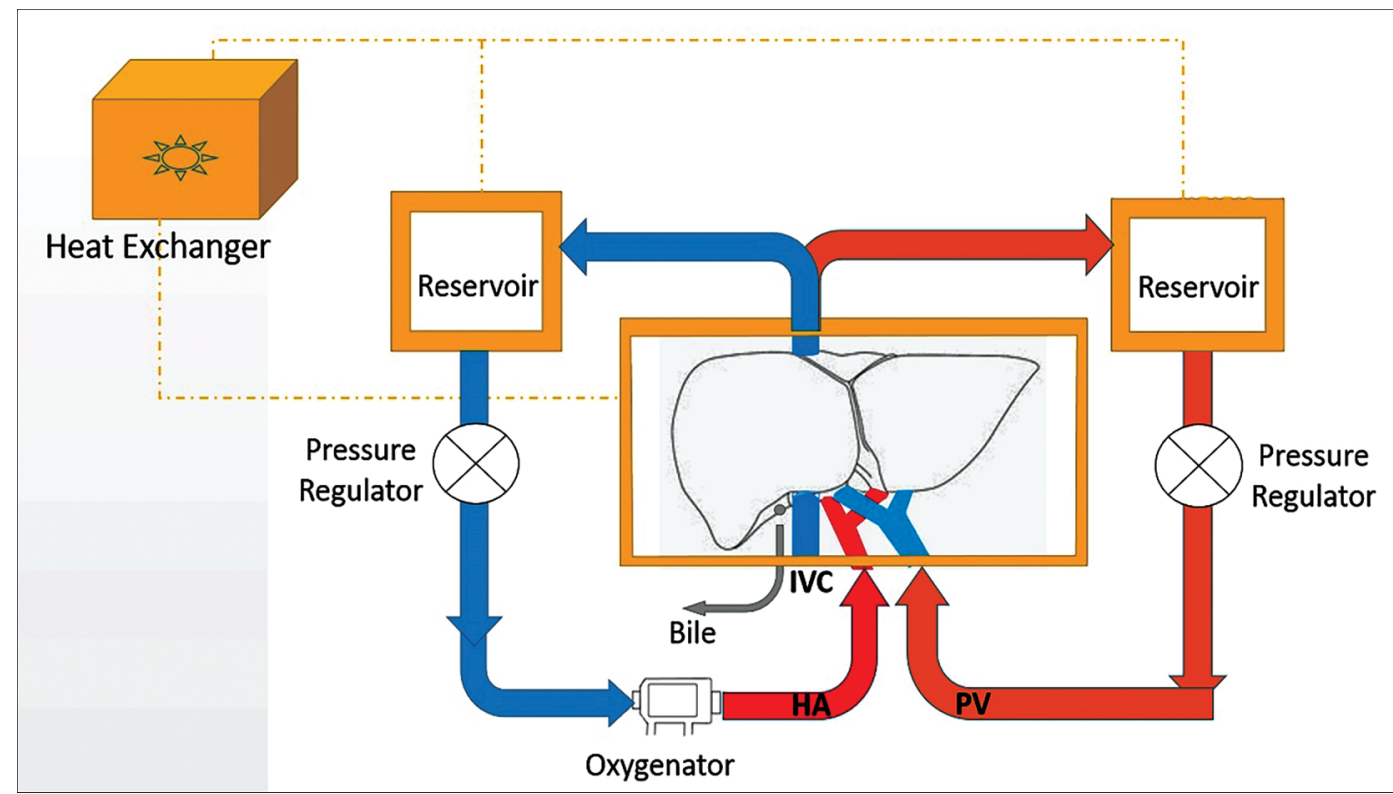

Fig. 1. Schematic of a normothermic ex-vivo liver perfusion circuit. Abbreviations: HA, hepatic artery; IVC, inferior vena cava; PV, portal Vein; IVC, Inferior Vena Cava.

become evident that ex-vivo perfusion holds the highest potential to increase the number of organs available for transplantation by expanding the donor pool. We sought to review the progress made in NMP, as well as to explore opportunities for future research.

\section{Pre-clinical studies}

\section{Large animal ex-vivo liver perfusion studies}

Early in the history of liver transplantation, the impact of graft ischemia on outcomes had become evident. In a first attempt at machine perfusion of the liver, Slapak et al. ${ }^{14}$ adapted the Debakey roller pump used in cardiac surgery into an apparatus for in-situ liver perfusion of the donor organ for transplantation. These initial perfusions lasted for about $8 \mathrm{~h}$, and were done under hypothermic conditions, given the success of hypothermic machine perfusion of the kidney. ${ }^{14,15}$ The development of the University of Wisconsin (UW) solution and its success in organ SCS, led to temporary abandonment of machine perfusion.

Despite the successes of the UW solution in cold storage, however, there was growing concern that SCS was not the ideal preservation method for liver grafts. Although, normothermic (regional) perfusion had been introduced by Otto et al. ${ }^{16}$ in 1958 , and later by Liem et al. ${ }^{17}$ as a treatment alternative for acute liver failure, normothermic ex-vivo perfusion did not enter the experimental scene until much later. The discovery and success of cyclosporine resulted in a significant increase in the number of organs being transplanted. With this success, however, came the issue of organ shortage.

While most ideal livers tolerated SCS well, marginal livers did not. Unfortunately, there was no good way to assess the organ quality prior to transplantation. As such, there was renewed interest in ex-vivo perfusion as a modality for organ evaluation and preservation. One of the earliest experiments in normothermic ex-vivo liver perfusion was performed by Ikeda et al. ${ }^{18}$ in 1990 , in which six porcine livers previously stored for
24 hours at $4^{\circ} \mathrm{C}$ with the UW solution underwent $3 \mathrm{~h}$ of sanguineous perfusion either at $32^{\circ} \mathrm{C}$ or $37^{\circ} \mathrm{C}$. These organs were compared to six other porcine livers perfused at $37^{\circ} \mathrm{C}$ immediately following procurement. The latter group had better portal and hepatic artery pressures as well as bile production compared to both groups that underwent $24 \mathrm{~h}$ of cold storage. ${ }^{18}$

Experiments on liver perfusion have equally been driven by the desire to optimize donation after cardiac death (DCD) livers prior to transplantation. In 2001, Schön et al. ${ }^{19}$ used a DCD porcine model to demonstrate successful preservation and transplantation of porcine livers. The organs were subjected to $1 \mathrm{~h}$ of warm ischemia time, followed by $4 \mathrm{~h}$ of NMP. While none of the recipients of the six livers subjected to $4 \mathrm{~h}$ of SCS survived for more than 7 days, all six recipients of livers from the NMP group survived. ${ }^{19}$ About the same time, other investigators showed that NMP could be extended to $72 \mathrm{~h}$, and was associated with better histological preservation, less transaminase release, improved bile production and superior synthetic/ metabolic function. ${ }^{20-24}$

More recent experiments have, again, demonstrated improvement in hemodynamics of the organ, reduction in markers of ischemia, better avoidance of ischemic and hypothermic injury (Ishak score) and better maintenance of hepatocyte viability in livers preserved by NMP. ${ }^{25-27}$ In an attempt to investigate the benefits of NMP on Maastricht Category 2 DCD donors, Fondevilla et al. ${ }^{28}$ used a DCD porcine model for which the donor pigs had undergone $90-\mathrm{m}$ cardiac arrest, after which they were divided into three groups. The first group was preserved by SCS, the second and third groups underwent $60 \mathrm{~m}$ of extracorporeal membrane oxygenation (ECMO) perfusion before being preserved by SCS or NMP for $4 \mathrm{~h}$ respectively. The investigators reported a $0 \%$ survival in the SCS group, $83 \%$ survival in the ECMO+SCS group and $100 \%$ survival in the ECMO+NMP group. Liver function, endothelial injury, cytokine and inflammatory response, and tissue necrosis was worst in the SCS group, followed by the ECMO+SCS group and being least in the ECMO+NMP group. ${ }^{28}$ These findings suggested that 
for those countries that allow Maastricht Category 2 DCD donation, the addition of NMP to the ECMO procedure could improve outcomes. The above findings suggest that NMP might be the best option to resuscitate organs exposed to extended warm ischemia time, as occurs in DCD donation.

Current procurement protocols require in-situ flushing with cold UW solution or histidine-tryptophan-ketoglutarate solution. There is concern regarding the effects of abrupt reperfusion on the organ. The concept of controlled oxygenated rewarming was introduced by Minor et al., ${ }^{29}$ initially as an adjunct to hypothermic perfusion. Banan et al. ${ }^{30}$ then combined gradual rewarming with NMP and reported improved INR, bile production, cholangiocyte function and decreased endothelial damage compared to immediate NMP after $4 \mathrm{~h}$ of cold storage. However, these results were inferior to the group that underwent NMP immediately without $4 \mathrm{~h}$ of cold storage. ${ }^{30}$

Some investigators have looked at optimizing the outcomes from NMP through the addition of other adjuncts to the circuit. In 2012, Chung et al. ${ }^{31}$ described the addition of a kidney to the liver NMP circuit. Although the authors saw no improvement in inflammatory cytokine expression, subsequent experiments did find improvements in glucose, $\mathrm{pH}$ and renal parameters such as urea and creatinine. Liver function did not appear to be compromised. Another study by the same group demonstrated that placing the kidney in the circuit before the liver, was more physiologic and produced better results compared to the liver-first circuit. ${ }^{32-34}$ Although en bloc liver-kidney transplants are not mainstream, this finding represents another area of exploration in patients undergoing combined liver-kidney transplantation.

Other adjuncts include addition of pharmacologic molecules to mitigate ischemic injury. Goldaracena et al. ${ }^{35}$ demonstrated improvement in liver function with the addition of anti-inflammatory strategies, including alprostadil and $\mathrm{n}$-acetylcysteine. It is worth noting, however, that other studies have shown decreased inflammation with NMP, even in the absence of added anti-inflammatory compounds. ${ }^{36}$ The concept of the addition of therapeutic compounds to the NMP perfusion circuit to improve outcomes following transplantation remains one of the areas of greatest potential growth in NMP technology and is, therefore, worth pursuing.

\section{Small animal ex-vivo liver perfusion studies}

There have been a limited number of rodent NMP studies due to their small size and lack of appropriate NMP technology, until recently. The smaller size and decreased complexity, however, offers the ability to study different aspects of ex-vivo NMP perfusion at reduced cost. One of the earliest successful ex-vivo perfusions of a mouse liver was performed by Baba et al. ${ }^{37}$ in 1988. In a proof-of-concept study, the group demonstrated stable ATP levels and minimal ischemia after $80 \mathrm{~m}$ of ex-vivo perfusion with oxygenated fluosol-DA. ${ }^{37}$ In 2008 , Talboom and colleagues $^{38}$ were able to successfully resuscitate Lewis rat livers using NMP after $45 \mathrm{~m}$ of warm ischemia and $2 \mathrm{~h}$ of simple cold storage. The animals that received these perfused livers had comparable survival to those with fresh livers, and did better than those who received livers stored by SCS only. ${ }^{38}$ The same group, in 2012, used a mouse DCD model to study machine perfusion/preservation at $20^{\circ} \mathrm{C}, 30^{\circ} \mathrm{C}$ and $37^{\circ} \mathrm{C}$. These livers were subsequently transplanted, allowing for evaluation of long-term outcomes. Results showed that compared to SCS, where none of the recipients survived past $12 \mathrm{~h}, 100 \%$ of the recipients from perfused livers (at all three temperatures) survived. ${ }^{39}$

Perk et al., ${ }^{40}$ using a DCD rat NMP model, developed a metabolic index of ischemic injury that could be used to evaluate ex-vivo perfused ischemic livers, helping to predict the function and, as such, suitability for transplantation. Using perfusate glucose, urea and lactate levels, the model was able to distinguish between fresh and ischemic livers with $90 \%$ specificity. ${ }^{40}$ A recent study by Op den Dries et al. ${ }^{41}$ showed that for both DCD and non-DCD rat livers, there was superior bile duct epithelial integrity and maintenance of morphology in NMP compared to SCS. ${ }^{41}$ Murine studies have also investigated the impact of liver steatosis on outcomes. Given that liver steatosis is major risk factor for primary non-function posttransplantation, ${ }^{42}$ many investigators have evaluated the use of the NMP circuit to de-fat the liver prior to transplantation, as well as mitigate IRI. Negrath et al., ${ }^{43}$ using various defatting cocktails, showed that successful defatting was associated with improved recovery from IRI. ${ }^{43}$ Preconditioning of livers on the NMP circuit with Nodosin, ${ }^{44}$ as well as with thrombomodulin, ${ }^{45}$ was also associated with improvement in endothelial damage and in IRI.

\section{Clinical studies}

\section{Ex-vivo perfusion studies using discarded human livers (w/o transplantation)}

Donor organ shortages and increasing use of marginal donor organs has been the major driver behind research on normothermic ex-vivo perfusion. One of the significant challenges in working with marginal organs is the absence of the necessary tools to adequately assess organs prior to transplantation. For this reason, DCD has a high organ discard rate. ${ }^{46}$ In the USA, about $10 \%$ of donated livers are discarded. ${ }^{47}$ NMP technology has emerged as a means of viability testing, preservation and resuscitation of would-be-discarded organs for transplantation. These discarded organs have, in turn, expedited the translation of ex-vivo perfusion from animals to humans.

In 2013, Op den Dries and colleagues ${ }^{48}$ demonstrated that this technology was feasible in human donor livers. Four discarded livers from donors underwent cold storage in histidine-tryptophan-ketoglutarate (one in UW solution) for 5-9 h, followed by $6 \mathrm{~h}$ of normothermic ex-vivo perfusion using oxygenated packed red blood cells and fresh frozen plasma. Histological examination before and after perfusion showed well-preserved morphology, without evidence of additional hepatocellular injury, biliary ischemia or sinusoidal damage. There was bile production from the livers and decreased lactate in the perfusate during the study, ${ }^{48}$ consistent with preserved hepatic function. Banan et al. ${ }^{49}$ showed a $10 \%$ reduction in macroglobular steatosis with the addition of exendin- 4 and L-carnitine to the NMP circuit. These findings could be useful in resuscitation of steatotic livers.

\section{Retrospective studies/case reports in ex-vivo liver perfusion}

There have been several clinical series demonstrating the use of NMP, but these have been limited to high-volume centers. In January 2016, Perera et al. ${ }^{50}$ reported on the first liver transplant from a graft resuscitated by NMP. The liver, which had been subjected to $109 \mathrm{~m}$ of warm ischemia and $422 \mathrm{~m}$ of cold ischemia, had been rejected by all other centers. The organ was resuscitated with 416 m of NMP, after which it was 
successfully transplanted. Overall ex-vivo time from crossclamp to reperfusion was $13 \mathrm{~h}$ and $58 \mathrm{~m}$. The recipient had an uneventful post-transplant course and was doing well at 15-month follow-up. ${ }^{50}$

Watson et al. ${ }^{51,52}$ also reported on similar successful cases, including one with $26 \mathrm{~h}$ ex-vivo (618-m cold storage, $8.5-\mathrm{h}$ NMP perfusion, 412-m SCS). In 2016, Angelico et al. ${ }^{53}$ conducted a retrospective review of six patients who had received liver grafts perfused with NMP as part of the OrganOx trial, comparing them to SCS recipients with similar donor and recipient characteristics. They found that NMP was associated with better intraoperative mean arterial pressures at $90 \mathrm{~s}$, less vasopressor requirement and less blood products compared to SCS. ${ }^{53}$ Mergental et al. ${ }^{54}$ also reported on a series of five livers that had been previously rejected (four DCD and one nonDCD with prolonged ischemia). Following resuscitation with the NMP circuit, the livers showed good viability (perfusate lactate, bile production, vascular flows, and liver appearance). The livers were all transplanted, and at 7 months post-transplant all patients were doing well. ${ }^{54}$

Watson et al. ${ }^{55}$ also recently published another series of 12 patients who received liver transplants from organs preserved by NMP. Six of the organs were perfused with perfusate at high oxygen tensions. In this group, they noted five cases of postreperfusion syndrome, four cases of sustained vasoplegia and one of primary non-function. The other six livers with perfusate containing physiologic oxygen tension did not show these complications, suggesting hyperoxia during NMP could be detrimental to the organ. ${ }^{55}$

\section{Clinical trials in ex-vivo perfusion}

In addition to the case series reported above, there have been a few Phase 1 pilot studies comparing NMP to SCS, or other modalities. In all three trials, the investigators used the OrganOx Metra ${ }^{12}$ device for normothermic perfusion. Table 1 summarizes some of the major findings from these trials.

The above-noted Phase 1 trials of normothermic ex-vivo perfusion have demonstrated its non-inferiority to SCS. ${ }^{56-58}$ It is worth noting, however, that none of the livers in these NMP trials were specifically labeled as extended criteria or marginal organs. In at least two of the trials (Ravikumar et al. ${ }^{56}$ and Selzner et $\left.a .^{58}\right), 80 \%$ of the livers were procured from brain dead donors. As previously noted, optimal organs generally tolerate SCS well, which is why this has been the standard for care the last two to three decades. So, although these have been non-inferiority trials, it is plausible that the true benefits of NMP will be become evident in trials with direct comparison using marginal livers. The authors of current trials have argued that NMP studies using standard livers are necessary to prove the feasibility of the technology before applying it to marginal livers, where it is expected to have the most benefit.

There are several Phase 2 and randomized clinical trials underway, and will hopefully address these concerns. The current trials have proved the feasibility of this technology in liver transplantation.

\section{Predictions of organ utility/discard}

There continues to be considerable debate about the best parameters to use to truly assess the organ prior to transplantation. Regardless of parameters, however, NMP provides a means of viability testing not afforded by SCS. Bile formation and secretion is generally accepted as a hallmark of liver graft function. Brockmann et al. ${ }^{24}$ have shown that bile output (as well as base excess, portal vein flow, and hepatocellular enzymes) were all markers of liver function in a porcine liver transplant model. Sutton and colleagues ${ }^{59}$ showed that high bile output of more than $30 \mathrm{~g}$ in $1 \mathrm{~h}$ was consistent with lower necrosis and improved potassium and transaminase levels, suggesting that this might be a good marker of viability.

Various perfusate markers have also been investigated as markers of liver function, viability and degree of hepatocyte damage. Karangwa and colleagues ${ }^{60}$ reported that a high D-dimer level early-on in the NMP circuit predicts severe ischemia of reperfusion and poor graft function. Beta-galactosidase level in perfusate, ${ }^{61}$ factor $\mathrm{V}$ level, ${ }^{62}$ perfusate $\mathrm{pH}^{62}$ and bicarbonate level ${ }^{59}$ have all been demonstrated as markers of viability. Other investigators have combined multiple parameters in an attempt to develop an algorithm than could be used to evaluate these organs. As previously noted, using a rat DCD model, Perk et al. ${ }^{40}$ developed a metabolic index of ischemic injury using perfusate glucose, urea and lactate levels capable of distinguishing between fresh and ischemic livers with $90 \%$ specificity. Bruinsma et al. ${ }^{63}$ advocated for the use of metabolomics (a comprehensive metabolic profile of the liver's condition) in combination with typical NMP parameters to better assess and characterize preserved livers.

Table 1. Completed clinical trials demonstrating successful liver transplantation using NMP livers

\begin{tabular}{|c|c|c|c|c|c|}
\hline Author, Year & Phase & Groups & Patients & Outcomes & Complications \\
\hline $\begin{array}{l}\text { Ravikumar, } \\
2016^{56}\end{array}$ & 1 & NMP vs SCS & $\begin{array}{l}20 \text { NMP to } 40 \text { cold } \\
\text { storage patients }\end{array}$ & $\begin{array}{l}\text { No difference in 30-day } \\
\text { survival, lower peak AST in } \\
\text { NMP group. }\end{array}$ & \\
\hline Bral, $2016^{57}$ & 1 & $\begin{array}{l}\text { NMP vs SCS } \\
\text { graft }\end{array}$ & $\begin{array}{l}10 \text { NMP vs. } 30 \text { SCS - } \\
\text { matched controls }\end{array}$ & $\begin{array}{l}\text { Non-inferior to SCS. No } \\
\text { difference in transaminases, } \\
\text { and graft survival at } 30 \text { days. } \\
\text { Longer ICU stay and hospital } \\
\text { LOS in NMP group. }\end{array}$ & $\begin{array}{l}1 \text { graft discarded, } \\
1 \text { reoperation and } 1 \text { renal } \\
\text { failure in the NMP group }\end{array}$ \\
\hline $\begin{array}{l}\text { Selzner, } \\
2016^{58}\end{array}$ & 1 & Single-arm & $10 \mathrm{NMP}$ vs. $30 \mathrm{CS}$ & $\begin{array}{l}\text { No difference in amylases, } \\
\text { graft function, graft loss or } \\
\text { mortality at } 3 \text { months }\end{array}$ & $\begin{array}{l}2 \text { organs discarded. } \\
1 \text { pneumonia in the NMP } \\
\text { arm, } 7 \text { patients in the } \\
\text { cold storage group had a } \\
\text { major complication. }\end{array}$ \\
\hline
\end{tabular}

Abbreviations: AST, aspartate aminotransferase; ICU, intensive care unit; LOS, length of stay. 
At this point, it remains unclear which factors best predict graft viability, as there have been no large randomized trials validating any of these parameters.

\section{HMP and subnormothermic perfusion}

Given the success with machine perfusion of the kidney, most of the early studies in machine perfusion of the liver were done at hypothermic and subnormothermic temperatures. In 1967, Slapak et al., ${ }^{14}$ fashioned a completely portable apparatus for hypothermic organ preservation including a 3-atmosphere oxygen concentrator, which was used successfully to preserve canine liver grafts ex-vivo before transplantation. ${ }^{14} \mathrm{HMP}$ was further promoted by the development of the UW solution. In 1990, Yanaga, ${ }^{15}$ working with Starzl, adapted the model MOX100 kidney perfusion machine into an ex-vivo liver perfusion system. HMP, however, did not gain full acceptance at that time due to the ease of SCS with the UW solution and the cumbersome nature of the HMP apparatus. Nevertheless, there was continued progress being made in the field, including multiple small and large animal studies.

In 2010, Guarrera et al. ${ }^{64}$ published the first prospective trial of HMP in human subjects. In this study, 20 adults who received HMP-preserved livers were compared to a matched group of cohorts who had received livers preserved by SCS. The investigators found no significant difference in overall outcome between the two groups. ${ }^{64}$ Since then, there have been more Phase 1 trials in hypothermic perfusion, including a study by Guarrera et al. ${ }^{65}$ in 2015 , which compared 31 extended criteria livers preserved by HMP to 30 matched SCS controls. The researchers noted significantly less biliary complications in the HMP group versus the SCS group (4 vs. 13, $p=0.016$ ). There was one primary graft non-function case in the HMP group and in the SCS group. Additionally, the hospital length of stay was significantly shorter in the HMP group. ${ }^{65}$

A similar study by Dutkowski et al. found significantly decreased liver injury (peak alanine aminotransferase, cholangiopathy, biliary complications, and graft survival) in DCD livers preserved by hypothermic oxygenated perfusion. They also compared hypothermic oxygenate machine perfusionperfused livers to brain dead donors preserved in a standard fashion (SCS) and found no significant difference. While HMP appears to be advantageous over SCS, there is no clear benefit of HMP over NMP. Additionally, there have been no randomized trials directly comparing HMP to NMP. Critics of HMP argue that, this modality does not allow for full functional assessment of the allograft, as the organs are not perfused at physiologic temperature.

\section{The future of normothermic ex-vivo perfusion}

The most immediate need and benefit of ex-vivo donor organ perfusion is organ assessment and potential repair prior to transplantation. The inability to adequately assess organs has led to relatively low rate of organ utility, despite an everincreasing need. ${ }^{66,67} \mathrm{NMP}$ and its ability to assess various organ parameters, including hepatic and portal artery resistance, bile production and changes in transaminases, provide valuable information that would aid in pre-transplant organ assessment. By providing a platform for pre-transplant assessment, NMP will serve to expand the donor pool, especially with regards to DCD and steatotic donations, which are often challenging to adequately assess. ${ }^{7,68,69}$
One of the major challenges in liver transplantation is cold ischemia time and the ability to reduce it. In 2009, Englesbe et $a .^{70}$ reported on Surgical Transplantation as one of the riskiest jobs in Medicine, owing to the need to procure and transplant organs as quickly as possible. ${ }^{70}$ In many hospitals, transplants are done at odd hours of the day, as organs must be transplanted immediately to decrease cold ischemia time. NMP ex-vivo perfusion allows the ability to preserve the organ for longer periods and to transplant it at a scheduled/desired time. Not only can patients get their affairs in order, but transplant surgeons will be able to have rest periods between procurement and transplantation.

Moreover, NMP has shown great promise in its ability to potentially mitigate the IRI associated with the procurement and preservation process, allowing for transplantation of improved organs. Extension of perfusion time, equally has potential applicability in combined organ transplantation. Ceulemans et al.. ${ }^{71}$ in 2014 , reported on the case of a patient with severe cystic fibrosis leading to pulmonary failure and liver fibrosis. The patient in that case underwent ex-vivo lung perfusion while the liver was being transplanted, as his liver disease was deemed too severe to allow for a lung transplant. ${ }^{71} \mathrm{~A}$ similar model could be applied in a patient with more severe lung disease or heart disease, who is unable to tolerate a liver transplant first. The liver could be placed on the NMP circuit, avoiding further cold ischemia time while the other organ is being transplanted.

Additionally, exploratory therapies are now associated with NMP. One suggestion has been the addition of mesenchymal stem cells to the NMP circuit, to hopefully induce immune tolerance in the graft. ${ }^{72}$ Anti-apoptotic agents and cell protective agents can be added into the perfusate as a means to reengineer suboptimal organs to better tolerate IRI. ${ }^{73}$ Although none of these have been employed in clinical trials or clinical practice, the opportunities abound. In a recent study, Goldaracena et al. ${ }^{74}$ reported on the recent use of the ex-vivo perfusion circuit to deliver Miravirsen to prevent hepatitis $C$ virus reinfection in porcine livers. This study, if translated to human livers, could have significant implications for the use hepatitis C virus-infected liver grafts, potentially in noninfected recipients. The technique could also be extended to potential donors with other systemic infections or infectious risk, expanding the donor pool.

\section{Conclusions}

Despite the great success of liver transplantation, the current donor organ shortage and the changes in donor demographics have placed an increased emphasis on the ability to safely use marginal organs. Although it has shown great promise in animal studies and early clinical series, there is still a paucity of robust human trials on NMP to date. The efficacy and superiority of this preservation technique to current methods will have to be demonstrated to justify the additional cost.

\section{Conflict of interest}

The authors have no conflict of interests related to this publication.

\section{Author contributions}

Contributed to the study design (CA, EWB, SMB), manuscript writing and critical revision (CA, EWB, BAW, SMB). 


\section{References}

[1] National Data - OPTN. 2017. Available from: https://optn.transplant.hrsa. gov/data/view-data-reports/national-data.

[2] 2012 Annual Data Report. Health Resources and Services Administration. 2017. Available from: https://srtr.transplant.hrsa.gov/annual_reports/2012/Default.aspx.

[3] UNOS. Transplant trends. 2017. Available from: https://www.unos. org/data/transplant-trends/.

[4] Punch JD, Hayes DH, LaPorte FB, McBride V, Seely MS. Organ donation and utilization in the United States, 1996-2005. Am J Transplant 2007;7: 1327-1338. doi: 10.1111/j.1600-6143.2007.01779.x.

[5] Op den Dries S, Sutton ME, Lisman T, Porte RJ. Protection of bile ducts in liver transplantation: looking beyond ischemia. Transplantation 2011;92: 373-379. doi: 10.1097/TP.0b013e318223a384.

[6] Merion RM, Goodrich NP, Feng S. How can we define expanded criteria for liver donors? J Hepatol 2006;45:484-488. doi: 10.1016/j.jhep. 2006.07.016.

[7] Jay C, Ladner D, Wang E, Lyuksemburg V, Kang R, Chang Y, et al. A comprehensive risk assessment of mortality following donation after cardiac death liver transplant - an analysis of the national registry. J Hepatol 2011;55: 808-813. doi: 10.1016/j.jhep.2011.01.040.

[8] Carrel A, Lindbergh CA. The culture of whole organs. Science 1935;81: 621-623. doi: 10.1126/science.81.2112.621.

[9] Belzer FO. Organ preservation: A personal perspective. Available from: https://web.stanford.edu/dept/HPS/transplant/html/belzer.html.

[10] Whitson BA, Black SM. Organ assessment and repair centers: The future of transplantation is near. World J Transplant 2014;4:40-42. doi: 10.5500/wjt. v4.i2.40.

[11] Organ Assist - Organ Perfusion Systems - Liver Assist. 2017. Available from: https://www.organ-assist.nl/products/liver-assist.

[12] OrganOx metra | Liver transportation and liver perfusion. 2017. Available from: http://www.organox.com/.

[13] Liver Preservation: TransMedics, Inc. 2017. Available from: http://www. transmedics.com/wt/page/ocsliverintro_med.

[14] Slapak M, Wigmore RA, MacLean LD. Twenty-four hour liver preservation by the use of continuous pulsatile perfusion and hyperbaric oxygen. Transplantation 1967;5:Suppl:1154-1158. doi: 10.1097/00007890-196707001-00052.

[15] Yanaga K, Makowka L, Lebeau G, Hwang RR, Shimada M, Kakizoe S, et al. A new liver perfusion and preservation system for transplantation research in large animals. J Invest Surg 1990;3:65-75. doi: 10.3109/08941939009140337.

[16] Otto JJ, Pender JC, Cleary JH, Sensenig DM, Welch CS. The use of a donor liver in experimental animals with elevated blood ammonia. Surgery 1958; 43:301-309.

[17] Liem DS, Waltuch TL, Eiseman B. Function of the ex-vivo pig liver perfused with human blood. Surg Forum 1964;15:90-91.

[18] Ikeda T, Yanaga K, Lebeau G, Higashi H, Kakizoe S, Starzl TE. Hemodynamic and biochemical changes during normothermic and hypothermic sanguinous perfusion of the porcine hepatic graft. Transplantation 1990;50:564-567. doi: 10.1097/00007890-199010000-00006.

[19] Schön MR, Kollmar O, Wolf S, Schrem H, Matthes M, Akkoc N, et al. Liver transplantation after organ preservation with normothermic extracorporeal perfusion. Ann Surg 2001;233:114-123. doi: 10.1097/00000658-20010100000017.

[20] Friend PJ, Imber C, St Peter S, Lopez I, Butler AJ, Rees MA. Normothermic perfusion of the isolated liver. Transplant Proc 2001;33:3436-3438. doi: 10. 1016/S0041-1345(01)02481-2.

[21] Butler AJ, Rees MA, Wight DG, Casey ND, Alexander G, White DJ, et al. Successful extracorporeal porcine liver perfusion for $72 \mathrm{hr}$. Transplantation 2002;73:1212-1218. doi: 10.1097/00007890-200204270-00005.

[22] Imber CJ, St Peter SD, Lopez de Cenarruzabeitia I, Pigott D, James T, Taylor $R_{\ell}$ et al. Advantages of normothermic perfusion over cold storage in liver preservation. Transplantation 2002;73:701-709. doi: 10.1097/00007890200203150-00008.

[23] St Peter SD, Imber CJ, Lopez I, Hughes D, Friend PJ. Extended preservation of non-heart-beating donor livers with normothermic machine perfusion. $\mathrm{Br}]$ Surg 2002;89:609-616. doi: 10.1046/j.1365-2168.2002.02052.x.

[24] Brockmann J, Reddy S, Coussios C, Pigott D, Guirriero D, Hughes D, et al. Normothermic perfusion: a new paradigm for organ preservation. Ann Surg 2009;250:1-6. doi: 10.1097/SLA.0b013e3181a63c10.

[25] Jamieson RW, Zilvetti M, Roy D, Hughes D, Morovat A, Coussios CC, et al. Hepatic steatosis and normothermic perfusion-preliminary experiments in a porcine model. Transplantation 2011;92:289-295. doi: 10.1097/TP. 0b013e318223d817.

[26] Boehnert MU, Yeung JC, Knaak JM, Selzner N, Selzner M. Normothermic acellular ex vivo liver perfusion (NEVLP) reduces liver and bile duct in DCD liver grafts. Am J Transplant 2013;13:3290. doi: 10.1111/ajt.12495.

[27] Nassar A, Liu Q, Farias K, D'Amico G, Tom C, Grady P, et al. Ex vivo normothermic machine perfusion is safe, simple, and reliable: results from a large animal model. Surg Innov 2015;22:61-69. doi: 10.1177/1553350614528383.
[28] Fondevila C, Hessheimer A], Maathuis MH, Muñoz J, Taurá P, Calatayud D, et al. Superior preservation of DCD livers with continuous normothermic perfusion. Ann Surg 2011;254:1000-1007. doi: 10.1097/SLA.0b013e31822b8b2f.

[29] Minor T, Efferz P, Fox M, Wohlschlaeger J, Lüer B. Controlled oxygenated rewarming of cold stored liver grafts by thermally graduated machine perfusion prior to reperfusion. Am J Transplant 2013;13:1450-1460. doi: 10. 1111/ajt.12235.

[30] Banan B, Xiao Z, Watson R, Xu M, Jia J, Upadhya GA, et al. Novel strategy to decrease reperfusion injuries and improve function of cold-preserved livers using normothermic ex vivo liver perfusion machine. Liver Transpl 2016;22: 333-343. doi: 10.1002/It.24352.

[31] Chung WY, Gravante G, Al-Leswas D, Alzaraa A, Sorge R, Ong SL, et al. Addition of a kidney to the normothermic ex vivo perfused porcine liver model does not increase cytokine response. J Artif Organs 2012;15:290-294. doi: 10.1007/s10047-012-0641-9.

[32] Chung WY, Gravante G, Al-Leswas D, Alzaraa A, Sorge R, Ong SL, et al. The autologous normothermic ex vivo perfused porcine liver-kidney model: improving the circuit's biochemical and acid-base environment. Am J Surg 2012;204:518-526. doi: 10.1016/j.amjsurg.2011.11.016.

[33] Chung WY, Gravante G, Al-Leswas D, Arshad A, Sorge R, Watson CC, et al. The development of a multiorgan ex vivo perfused model: results with the porcine liver-kidney circuit over 24 hours. Artif Organs 2013;37:457-466. doi: 10.1111/aor.12003.

[34] Chung WY, Gravante G, Eltweri A, Sorge R, Ong SL, Pollard C, et al. The "kidney-liver" multiorgan ex vivo perfused model improves the circuit's biochemical milieu during perfusion compared to the "liver-kidney" counterpart. J Artif Organs 2015;18:151-161. doi: 10.1007/s10047-014-0813-x.

[35] Goldaracena N, Echeverri J, Spetzler VN, Kaths JM, Barbas AS, Louis KS, et al. Anti-inflammatory signaling during ex vivo liver perfusion improves the preservation of pig liver grafts before transplantation. Liver Transpl 2016:22:1573-1583. doi: 10.1002/lt.24603.

[36] Sadowsky D, Zamora R, Barclay D, Yin J, Fontes P, Vodovotz Y. Machine perfusion of porcine livers with oxygen-carrying solution results in reprogramming of dynamic inflammation networks. Front Pharmacol 2016;7:413. doi: 10.3389/fphar.2016.00413.

[37] Baba S, Nakai K, Mizutani K. Ex-vivo perfusion of surgically removed organs. Biomater Artif Cells Artif Organs 1988;16:623-624. doi: 10.3109/ 10731198809132618

[38] Tolboom H, Milwid JM, Izamis ML, Uygun K, Berthiaume F, Yarmush ML. Sequential cold storage and normothermic perfusion of the ischemic rat liver. Transplant Proc 2008;40:1306-1309. doi: 10.1016/j.transproceed. 2008.03.100.

[39] Tolboom H, Izamis ML, Sharma N, Milwid JM, Uygun B, Berthiaume F, et al. Subnormothermic machine perfusion at both $20^{\circ} \mathrm{C}$ and $30^{\circ} \mathrm{C}$ recovers ischemic rat livers for successful transplantation. J Surg Res 2012;175:149-156. doi: 10.1016/j.jss.2011.03.003.

[40] Perk S, Izamis ML, Tolboom H, Uygun B, Yarmush ML, Uygun K. A fitness index for transplantation of machine-perfused cadaveric rat livers. BMC Res Notes 2012;5:325. doi: 10.1186/1756-0500-5-325.

[41] Op den Dries $S$, Karimian N, Westerkamp AC, Sutton ME, Kuipers $M$, Wiersema-Buist J, et al. Normothermic machine perfusion reduces bile duct injury and improves biliary epithelial function in rat donor livers. Liver Transpl 2016;22:994-1005. doi: 10.1002/It.24436.

[42] Perez-Daga JA, Santoyo J, Suárez MA, Fernández-Aguilar JA, Ramírez C, Rodríguez-Cañete $A$, et al. Influence of degree of hepatic steatosis on graft function and postoperative complications of liver transplantation. Transplant Proc 2006;38:2468-2470. doi: 10.1016/j.transproceed.2006.08.077.

[43] Nagrath D, Xu H, Tanimura Y, Zuo R, Berthiaume F, Avila M, et al. Metabolic preconditioning of donor organs: defatting fatty livers by normothermic perfusion ex vivo. Metab Eng 2009;11:274-283. doi: 10.1016/j.ymben.2009. 05.005 .

[44] Wang CF, Wang ZY, Tao SF, Ding J, Sun LJ, Li JY, et al. Preconditioning donor liver with Nodosin perfusion lessens rat ischemia reperfusion injury via heme oxygenase-1 upregulation. J Gastroenterol Hepatol 2012;27:832-840. doi: 10.1111/j.1440-1746.2011.06966.x.

[45] Kashiwadate T, Miyagi S, Hara Y, Akamatsu Y, Sekiguchi S, Kawagishi N, et al. Soluble thrombomodulin ameliorates ischemia-reperfusion injury of liver grafts by modulating the proinflammatory role of high-mobility group box 1 . Tohoku J Exp Med 2016:239:315-323. doi: 10.1620/tjem.239.315.

[46] Orman ES, Barritt AS 4th, Wheeler SB, Hayashi PH. Declining liver utilization for transplantation in the United States and the impact of donation after cardiac death. Liver Transpl 2013;19:59-68. doi: 10.1002/It.23547.

[47] Carpenter D, Mohan S, Halazun K, Verna E, Chiles M, Charak G, et al. National trends in liver discards: The weekend effect. Am J Transplant 2016;16:C59. Available from: http://atcmeetingabstracts.com/abstract/national-trends-in-liver-discards-the-weekend-effect/.

[48] op den Dries S, Karimian N, Sutton ME, Westerkamp AC, Nijsten MW, Gouw AS, et al. Ex vivo normothermic machine perfusion and viability testing of discarded human donor livers. Am J Transplant 2013;13:1327-1335. doi: 10.1111/ajt.12187. 
[49] Banan B, Watson R, Xu M, Lin Y, Chapman W. Development of a normothermic extracorporeal liver perfusion system toward improving viability and function of human extended criteria donor livers. Liver Transpl 2016;22: 979-993. doi: 10.1002/It.24451.

[50] Perera T, Mergental H, Stephenson B, Roll GR, Cilliers H, Liang R, et al. First human liver transplantation using a marginal allograft resuscitated by normothermic machine perfusion. Liver Transpl 2016;22:120-124. doi: 10. $1002 /$ It.24369.

[51] Watson C], Randle LV, Kosmoliaptsis V, Gibbs P, Allison M, Butler AJ. 26-hour storage of a declined liver before successful transplantation using ex vivo normothermic perfusion. Ann Surg 2017;265:e1-e2. doi: 10.1097/SLA. 0000000000001834.

[52] Watson C], Kosmoliaptsis V, Randle LV, Russell NK, Griffiths WJ, Davies S, et al. Preimplant normothermic liver perfusion of a suboptimal liver donated after circulatory death. Am J Transplant 2016;16:353-357. doi: 10.1111/ajt. 13448.

[53] Angelico R, Perera MT, Ravikumar R, Holroyd D, Coussios C, Mergental $H_{\text {, }}$ et al. Normothermic machine perfusion of deceased donor liver grafts is associated with improved postreperfusion hemodynamics. Transplant Direct 2016;2:e97. doi: 10.1097/TXD.0000000000000611.

[54] Mergental H, Perera MT, Laing RW, Muiesan P, Isaac JR, Smith A, et al. Transplantation of declined liver allografts following normothermic ex-situ evaluation. Am J Transplant 2016;16:3235-3245. doi: 10.1111/ajt.13875.

[55] Watson CJE, Kosmoliaptsis V, Randle LV, Gimson AE, Brais R, Klinck JR, et al. Normothermic perfusion in the assessment and preservation of declined livers before transplantation: hyperoxia and vasoplegia-important lessons from the first 12 cases. Transplantation 2017;101:1084-1098. doi: 10. 1097/TP.0000000000001661.

[56] Ravikumar R, Jassem W, Mergental H, Heaton N, Mirza D, Perera MT, et al. Liver transplantation after ex vivo normothermic machine preservation: a phase 1 (first-in-man) clinical trial. Am J Transplant 2016;16:1779-1787. doi: 10.1111/ajt.13708.

[57] Bral M, Gala-Lopez B, Bigam D, Kneteman N, Malcolm A, Livingstone S, et al. Preliminary single-center canadian experience of human normothermic ex vivo liver perfusion: results of a clinical trial. Am J Transplant 2017;17:10711080. doi: 10.1111/ajt.14049.

[58] Selzner M, Goldaracena N, Echeverri J, Kaths JM, Linares I, Selzner N, et al. Normothermic ex vivo liver perfusion using steen solution as perfusate for human liver transplantation: First North American results. Liver Transpl 2016;22:1501-1508. doi: 10.1002/lt.24499.

[59] Sutton ME, op den Dries S, Karimian N, Weeder PD, de Boer MT, WiersemaBuist J, et al. Criteria for viability assessment of discarded human donor livers during ex vivo normothermic machine perfusion. PLoS One 2014;9: e110642. doi: 10.1371/journal.pone.0110642.

[60] Karangwa SA, Burlage LC, Adelmeijer J, Karimian N, Westerkamp AC, Matton $A P$, et al. Activation of fibrinolysis, but not coagulation, during end-ischemic ex situ normothermic machine perfusion of human donor livers. Transplantation 2017;101:e42-e48. doi: 10.1097/TP.0000000000001562.
[61] St Peter SD, Imber CJ, De Cenarruzabeitia IL, McGuire J, James T, Taylor R, et al. Beta-galactosidase as a marker of ischemic injury and a mechanism for viability assessment in porcine liver transplantation. Liver Transpl 2002;8: 21-26. doi: 10.1053/jlts.2002.30344.

[62] St Peter SD, Imber C], Kay J, James T, Friend PJ. Hepatic control of perfusate homeostasis during normothermic extrocorporeal preservation. Transplant Proc 2003;35:1587-1590. doi: 10.1016/S0041-1345(03)00530-X.

[63] Bruinsma BG, Sridharan GV, Weeder PD, Avruch JH, Saeidi N, Özer S, et al. Metabolic profiling during ex vivo machine perfusion of the human liver. Sci Rep 2016;6:22415. doi: 10.1038/srep22415.

[64] Guarrera JV, Henry SD, Samstein B, Odeh-Ramadan R, Kinkhabwala M, Goldstein $\mathrm{MJ}$, et al. Hypothermic machine preservation in human liver transplantation: the first clinical series. Am J Transplant 2010;10:372-381. doi: 10. $1111 /$ j.1600-6143.2009.02932.x.

[65] Guarrera JV, Henry SD, Samstein B, Reznik E, Musat C, Lukose TI, et al. Hypothermic machine preservation facilitates successful transplantation of "orphan" extended criteria donor livers. Am J Transplant 2015;15:161-169. doi: 10.1111/ajt.12958.

[66] Kim WR, Smith JM, Skeans MA, Schladt DP, Schnitzler MA, Edwards EB, et al. OPTN/SRTR 2012 Annual Data Report: liver. Am J Transplant 2014;14 Suppl 1:69-96. doi: 10.1111/ajt.12581.

[67] Kim WR, Lake JR, Smith JM, Skeans MA, Schladt DP, Edwards EB, et al. OPTN/SRTR 2013 Annual Data Report: liver. Am J Transplant 2015;15 Suppl 2:1-28. doi: 10.1111/ajt.13197.

[68] Feng S, Goodrich NP, Bragg-Gresham JL, Dykstra DM, Punch JD, DebRoy MA, et al. Characteristics associated with liver graft failure: the concept of a donor risk index. Am J Transplant 2006;6:783-790. doi: 10.1111/j.16006143.2006.01242.x.

[69] Jadlowiec CC, Taner T. Liver transplantation: Current status and challenges. World J Gastroenterol 2016;22:4438-4445. doi: 10.3748/wjg.v22.i18.4438

[70] Englesbe MJ, Merion RM. The riskiest job in medicine: transplant surgeon and organ procurement travel. Am J Transplant 2009;9:2406-2415. doi: 10. $1111 /$ j.1600-6143.2009.02774.x.

[71] Ceulemans LJ, Monbaliu D, Verslype C, van der Merwe S, Laleman W, Vos R, et al. Combined liver and lung transplantation with extended normothermic lung preservation in a patient with end-stage emphysema complicated by drug-induced acute liver failure. Am J Transplant 2014;14:2412-2416. doi: 10.1111/ajt.12856

[72] Van Raemdonck D, Neyrinck A, Rega F, Devos T, Pirenne J. Machine perfusion in organ transplantation: a tool for ex-vivo graft conditioning with mesenchymal stem cells? Curr Opin Organ Transplant 2013;18:24-33. doi: 10 1097/MOT.0b013e32835c494f.

[73] Ali F, Dua A, Cronin DC. Changing paradigms in organ preservation and resuscitation. Curr Opin Organ Transplant 2015;20:152-158. doi: 10 1097/MOT.0000000000000180.

[74] Goldaracena N, Spetzler VN, Echeverri ], Kaths JM, Cherepanov V, Persson R, et al. Inducing hepatitis $C$ virus resistance after pig liver transplantation-a proof of concept of liver graft modification using warm ex vivo perfusion. Am J Transplant 2017;17:970-978. doi: 10.1111/ajt.14100. 